\title{
OBSERVATIONS OF NEAR-INERTIAL SURFACE CURRENTS AT PALAU
}

By Mika Siegelman,

Mark A. Merrifield,

Eric Firing,

Jennifer A. MacKinnon,

Matthew H. Alford, Gunnar Voet,

Hemantha W. Wijesekera,

Travis A. Schramek,

Kristin L. Zeiden,

and Eric J. Terrill
ABSTRACT. An impulsive or rotary wind stress can excite near-inertial oscillations (NIOs) in the surface mixed layer. Although previous work shows that coastal boundaries modify NIOs, few studies have explored their behavior near island topography. Understanding how topography modifies NIOs provides insight into physical processes that contribute to local mixing, which enhances biological richness near islands. Here, encounters between NIOs and the island chain of Palau are examined using moored current meter measurements from a 10-month field study. Near-inertial currents are surface intensified, where typical speeds of $0.15 \mathrm{~m} \mathrm{~s}^{-1}$ in the surface layer are twice those below $50 \mathrm{~m}$. At moorings farthest from Palau topography, nearinertial surface currents are intermittent and clockwise rotational, suggestive of wind-generated NIOs. Closer to the topography, near-inertial currents become more rectilinear, with enhanced energy at the northern and southern tips compared to along the north-south oriented coastline of the elongated island chain. The first empirical orthogonal function of near-inertial vector surface currents ( $62 \%$ of the total variance in the near-inertial band) reveals a broadly uniform flow that spans the northern and southern extents of the island, suggestive of a slab-like NIO response to wind stress, modified as the island topography blocks the flow. To further characterize the impact of the topography on near-inertial currents, a cluster of moorings at the northern tip of Palau is used to estimate vorticity, which increases as near-inertial current speeds increase. Near-inertial vorticity is attributed to frictional torque caused by the topographically enhanced near-inertial currents brushing against the northern tip of Palau.

IN PLAIN WORDS. We characterize the flow around the island chain of Palau using current observations in order to explore how topography modifies near-inertial oscillations (NIOs), which are wind-generated rotary currents in the surface mixed layer. An understanding of these modifications should prove useful in helping to explain the physical processes that contribute to the local mixing that enhances biological richness near islands. 


\section{INTRODUCTION}

The Flow Encountering Abrupt Topography (FLEAT) experiment provided an opportunity to study flows that encounter an island group over a broad range of temporal and spatial scales. The study site was Palau in the western tropical Pacific, centered at $7^{\circ} \mathrm{N}$ and $134^{\circ} \mathrm{E}$ (Figure 1) and extending approximately $200 \mathrm{~km}$ meridionally and $20 \mathrm{~km}$ zonally. Despite the oligotrophic surface waters in this region, Palau is exceptionally biologically diverse, largely because of ensuing wake dynamics when flows encounter the island chain, most notably lee eddies and internal waves (Colin, 2009). These physical phenomena enhance biological productivity around islands by enhancing local mixing and vertically transporting deep, nutrient-rich water to the euphotic zone (Gove et al., 2016). Winddriven oscillatory currents, known as near-inertial oscillations (NIOs), potentially contribute to wake formation; however, their behavior is poorly understood near island topography.

The island chain of Palau is situated on a shallow platform (Figure 1) that includes the main volcanic island of Babeldaob, a group of smaller coral islands to the south, and a shallow lagoon bordered by barrier reefs (Colin, 2009). At the southern tip of the platform, the island of Peleliu is separated from the small island of Angaur to the south by a channel ( $>200 \mathrm{~m}$ deep) and shallow bank ( $\approx 20 \mathrm{~m}$ deep). The submerged Velasco Reef, located at the northern end of Palau (northern bounded area in Figure 1), constitutes a nearly vertical wall that extends north and deepens to over 1,000 m barely a kilometer from the reef edge, making it an excellent site for examining how an island without a shelf modifies near-inertial oscillations.

NIOs, anticyclonic rotary currents that are prevalent in the ocean's surface mixed layer (e.g., Pollard, 1980; D’Asaro, 1985), can be excited by impulsive wind forcing or by winds that vary at near-inertial frequencies. They are often observed following the passage of energetic storms (e.g., Shay and Elsberry, 1987; D’Asaro et al., 1995; Firing et al., 1997), with reported current speeds up to $1.7 \mathrm{~m} \mathrm{~s}^{-1}$ (Price et al., 1994). NIOs play an important role in ocean mixing and in energy transfer from the atmosphere to the ocean interior (Simmons and Alford, 2012; Alford et al., 2016). They generate vertical shears at the base of the mixed layer that enhance turbulent mixing (Alford and Gregg, 2001; Johnston and Rudnick, 2009; Johnston et al., 2016), and their energy gradually radiates downward and away from their source region as internal waves that contribute to deepocean mixing (Simmons and Alford, 2012; Johnston et al., 2016).

Pollard and Millard (1970) described the generation of NIOs in the surface mixed layer in terms of a homogeneous slab model forced by spatially uniform winds. Despite the simplicity of their model, they were able to replicate the phase, amplitude, and intermittency of observed mixed layer inertial oscillations. The slab model has been compared to observed currents in numerous observational studies (e.g., D’Asaro, 1985; Paduan et al., 1989; Firing et al., 1997; Alford, 2001), emphasizing the general link between local wind forcing and NIOs.

The assumption that the upper ocean responds to wind forcing as an unimpeded slab is not valid near coastal boundaries. Kundu et al. (1983) explored theoretically wind-generated NIOs on a continental shelf. They showed how impulsive wind forcing generates inertial oscillations that decay toward the coast at all depths to
FIGURE 1. The island chain of Palau showing $0 \mathrm{~m}, 100 \mathrm{~m}$, $1,000 \mathrm{~m}, 2,000 \mathrm{~m}$, and 3,000 m depth contours. Red markers indicate deepwater (>400 m) moorings, and green stars indicate shallow water $(<130 \mathrm{~m})$ bottommounted acoustic Doppler current profilers (ADCPS). Red circles denote the three moorings (F2, F3, and F6) used to calculate the vertical component of relative vorticity. The blue pentagon northwest of Peleliu locates the weather station.
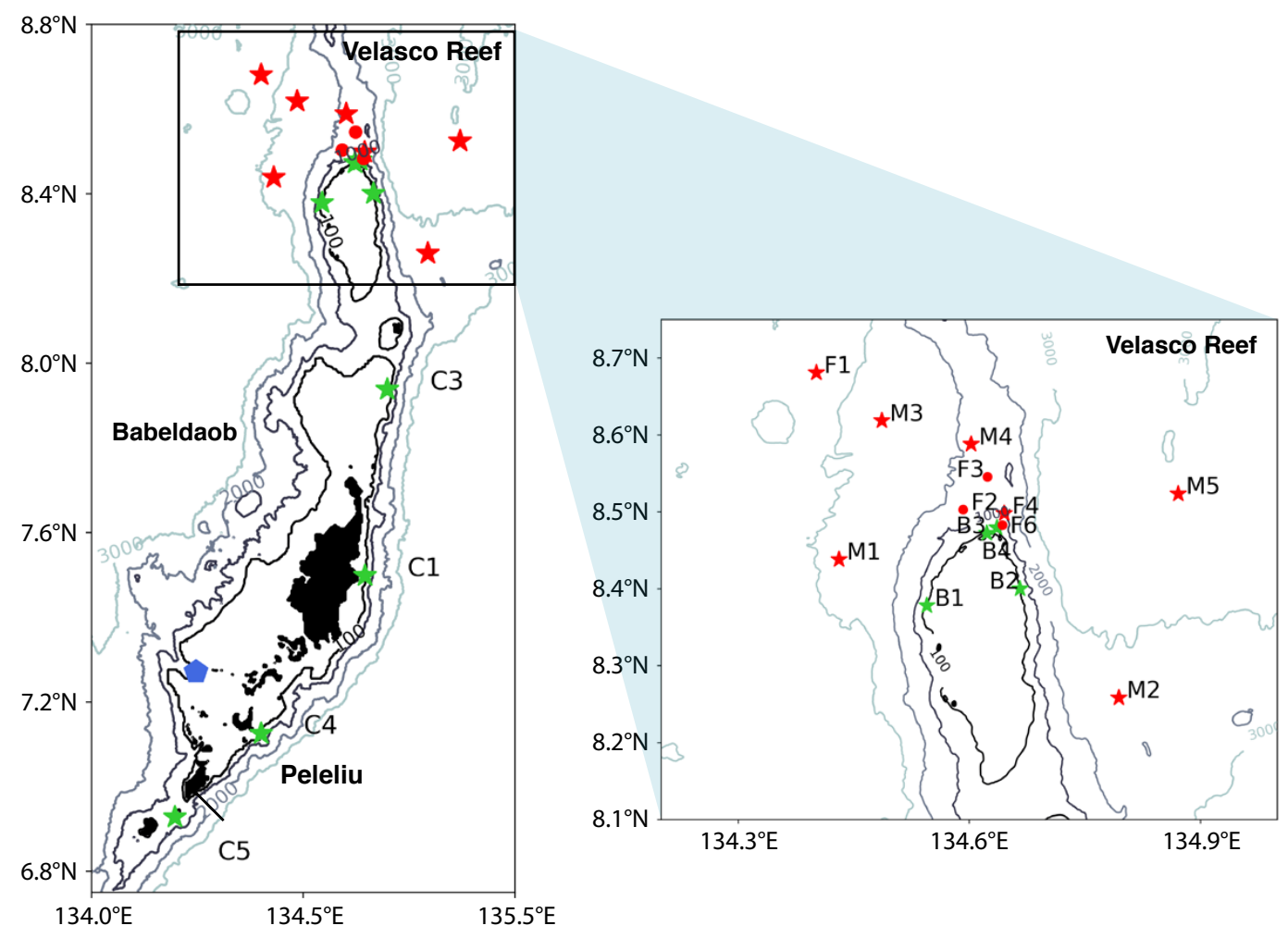
satisfy a necessary condition of no flow through the boundary. They termed this decay "coastal inhibition." Additionally, near-inertial internal waves radiate away from the boundary due to a geostrophic adjustment process. Similar to the analytical solution by Kundu et al. (1983), many subsequent observational studies of wind-generated NIOs near coasts have shown this decay of near-inertial energy near topography (Schahinger, 1988; Tintoré et al., 1995; Shearman, 2005; Fontán and Cornuelle, 2015).

The behavior of wind-generated NIOs near islands has received relatively little attention. In particular, the degree to which island boundaries lead to coastal inhibition of NIOs is unclear. LonguetHiggins (1970) found an analytical solution for an oscillatory current near a circular island in a rotating fluid: when the rotary current oscillates at the Coriolis frequency, the surface elevation travels anticyclonically around the cylinder, and the along-boundary velocity is enhanced.

A number of studies have examined steady or oscillatory flows encoun- tering island topography and the ensuing wake response (Pattiaratchi et al., 1987; Heywood et al., 1990; Coutis and Middleton, 1999; Dong et al., 2007). For example, the generation of island wake eddies by oscillatory tidal flows was reported by Wolanski et al. (1984), but to our knowledge the contribution of oscillatory NIOs to island wakes has not been considered. NIOs have been reported in the vicinity of O'ahu, Hawai' $i$, using high-frequency radar observations (Trujillo, 2018), and the relationship between these motions and local wind forcing was found to be complicated in part due to strong interactions of the NIOs with subinertial currents.

In this study, we use moored observations from FLEAT to characterize the flow around Palau and to examine flow-island interactions, with particular interest in near-inertial currents, which exhibit considerable spatial variability along the island chain (Figure 1). We first describe the moored observations from the FLEAT array and the slab model used to assess the wind-driven NIOs. Then,

TABLE 1. Mooring array information.

\begin{tabular}{|c|c|c|c|c|c|}
\hline Site Name & Lat $\left.{ }^{\circ} \mathbf{N}\right)$ & Lon ( ${ }^{\circ}$ E) & Start Date & End Date & Depth (m) \\
\hline M1 & 8.438 & 134.431 & $5 / 20 / 2016$ & $4 / 4 / 2017$ & 2,600 \\
\hline M2 & 8.258 & 134.794 & $5 / 20 / 2016$ & $3 / 31 / 2017$ & 2,610 \\
\hline M3 & 8.618 & 134.487 & $5 / 23 / 2016$ & $4 / 3 / 2017$ & 2,846 \\
\hline M4 & 8.605 & 134.602 & $5 / 22 / 2016$ & $10 / 8 / 2016$ & 1,350 \\
\hline M5 & 8.523 & 134.871 & $5 / 20 / 2016$ & $4 / 1 / 2017$ & 3,610 \\
\hline F1 & 8.6806 & 134.4015 & $6 / 5 / 2016$ & $4 / 14 / 2017$ & 3,390 \\
\hline F2 & 8.5027 & 134.5922 & $6 / 3 / 2016$ & $4 / 15 / 2017$ & 1,515 \\
\hline F3 & 8.5453 & 134.6236 & $6 / 4 / 2016$ & $4 / 15 / 2017$ & 1,666 \\
\hline F4 & 8.4977 & 134.6454 & $6 / 4 / 2016$ & $4 / 14 / 2017$ & 880 \\
\hline F6 & 8.4827 & 134.6429 & $6 / 23 / 2016$ & $4 / 13 / 2017$ & 434 \\
\hline B1 & 8.378 & 134.545 & $5 / 25 / 2016$ & $4 / 5 / 2017$ & 110 \\
\hline B2 & 8.400 & 134.666 & $5 / 25 / 2016$ & $4 / 5 / 2017$ & 135 \\
\hline B3 & 8.472 & 134.623 & $5 / 26 / 2016$ & $2 / 27 / 2017$ & 53 \\
\hline B4 & 8.479 & 134.636 & $11 / 26 / 2016$ & $3 / 25 / 2017$ & 78 \\
\hline C1 & 7.4971 & 134.6461 & $4 / 2 / 2015$ & $3 / 23 / 2017$ & 14 \\
\hline C3 & 7.9371 & 134.6994 & $3 / 19 / 2014$ & $3 / 24 / 2017$ & 17 \\
\hline C4 & 7.1247 & 134.4015 & $4 / 1 / 2015$ & $3 / 25 / 2017$ & 17 \\
\hline C5 & 6.9302 & 134.1994 & $3 / 29 / 2014$ & $5 / 18 / 2018$ & 18 \\
\hline & & & & & \\
\hline
\end{tabular}

general features of the upper ocean subinertial currents are described, as well as the temporal and spatial variability of the near-inertial currents. A subset of moorings is used to estimate vorticity generation at Velasco Reef, with focus on the near-inertial band. We conclude with a summary of our main results.

\section{DATA AND METHODS}

Current observations were obtained from an array of 10 deepwater moorings and eight bottom-mounted acoustic Doppler current profilers (ADCPs) deployed around Palau from May 2016 through April 2017 (Table 1, Figure 1). The deepwater moorings ( $\mathrm{M}$ and $\mathrm{F}$ ) were deployed in $400 \mathrm{~m}$ to 3,390 $\mathrm{m}$ water depth around the northern tip of Velasco Reef. Each mooring included $75 \mathrm{kHz}$ and $300 \mathrm{kHz}$ RDI ADCPs. Here, we focus on observations from the surface mixed layer (16-50 m), which was primarily resolved by the $300 \mathrm{kHz}$ ADCPs. The mixed layer depth (not shown) was defined using CTDs obtained concurrently by gliders near Velasco Reef (Zeiden et al., 2019). Velocity measurements shallower than $16 \mathrm{~m}$ were not included in surface averages to eliminate side-lobe contaminated data and to maintain consistent surface layer depth averages across the array. These shallow, upward-looking ADCPs had a vertical resolution of $4 \mathrm{~m}$ and ensemble lengths of six or 20 minutes. Layover corrections were made to the ADCP data based on pressure sensor measurements on the mooring line. Currents from bottom-mounted Nortek Acoustic Wave and Current Profilers (AWACs) and RDI $600 \mathrm{kHz}$ Sentinel ADCPs were collected in shallow water (14 m to $135 \mathrm{~m}$ ) around the northern half of Velasco Reef, the eastern side of Babeldaob, and the southern tip of Peleliu. These ADCPs sampled at a vertical resolution of $1 \mathrm{~m}$ with ensembles of 12 minutes. ADCP velocities were band-passed to isolate nearinertial frequencies ( $0.8 f$ to $1.2 f$, where $f$ is the Coriolis frequency) using an eighth-order Butterworth filter.

The vertical component of relative vor- 
ticity, $\zeta=\partial v / \partial x-\partial u / \partial y$, was computed from the triangular array comprised of moorings F2, F3, and F6 at the northern tip of Velasco Reef. For each velocity component, fitting a plane through the values at the three moorings yields the partial derivatives needed to calculate $\zeta$.

In situ wind observations were obtained from an XMET meteorological station deployed to the west of Babeldaob $\left(7.2706^{\circ} \mathrm{N}, 134.2470^{\circ} \mathrm{E}\right)$. The station consisted of a Vaisala WXT520 that collected hourly data for atmospheric pressure, temperature, humidity, rain, wind direction, speed, and gust at $4.5 \mathrm{~m}$ above sea level. Additionally, a numerical weather prediction model from the European Centre for Medium-Range Weather Forecasts (ECMWF) was used to provide spatial coverage of the winds. The model output is hourly with spatial resolution of $0.125^{\circ}$. There is significant correlation between the in situ winds and the model winds, with $\mathrm{r}^{2}$ values of 0.69 and 0.83 for zonal and meridional wind velocities, respectively. Wind stress $(\vec{\tau})$ was computed from the observed wind speed using the Large and Pond (1981) formulation.

The expected near-inertial component of the mixed layer currents was estimated from the Pollard and Millard (1970) slab model using wind stress from the meteorological station. Model parameters were set to a constant mixed layer depth of $50 \mathrm{~m}$, a density of $1,000 \mathrm{~kg} \mathrm{~m}^{-3}$, a Coriolis parameter of $2.09 \times 10^{-5} \mathrm{~s}^{-1}$ (period $=3.36$ days), and a damping value of $9.72 \times 10^{-7} \mathrm{~s}^{-1}$ $\left(\mathrm{e}^{-1}\right.$ decay time $=11.9$ days $)$.

\section{RESULTS AND DISCUSSION}

Observed flow Characteristics

Surface-averaged currents near Velasco Reef $(16-50 \mathrm{~m})$ and Peleliu $(3-18 \mathrm{~m})$ are broadband and strong, reaching peak speeds of approximately $1.30 \mathrm{~m} \mathrm{~s}^{-1}$ and $2.42 \mathrm{~m} \mathrm{~s}^{-1}$, respectively (Figure 2a,b,d,e). The observations shown were made at the deepwater mooring deployed to the east of Velasco Reef (M2) to highlight conditions upstream of the mean westward flow during the deployment, and at the bottom-mounted ADCP to the south of Peleliu (C5). Rotary spectra of the currents (Figure 2c,f) reveal energetic spectral peaks in the near-inertial frequency band $(0.8 f$ to $1.2 f)$ and at tidal frequencies (semidiurnal and diurnal). Nearinertial fluctuations account for approximately $10 \%$ and $11 \%$ of the total current
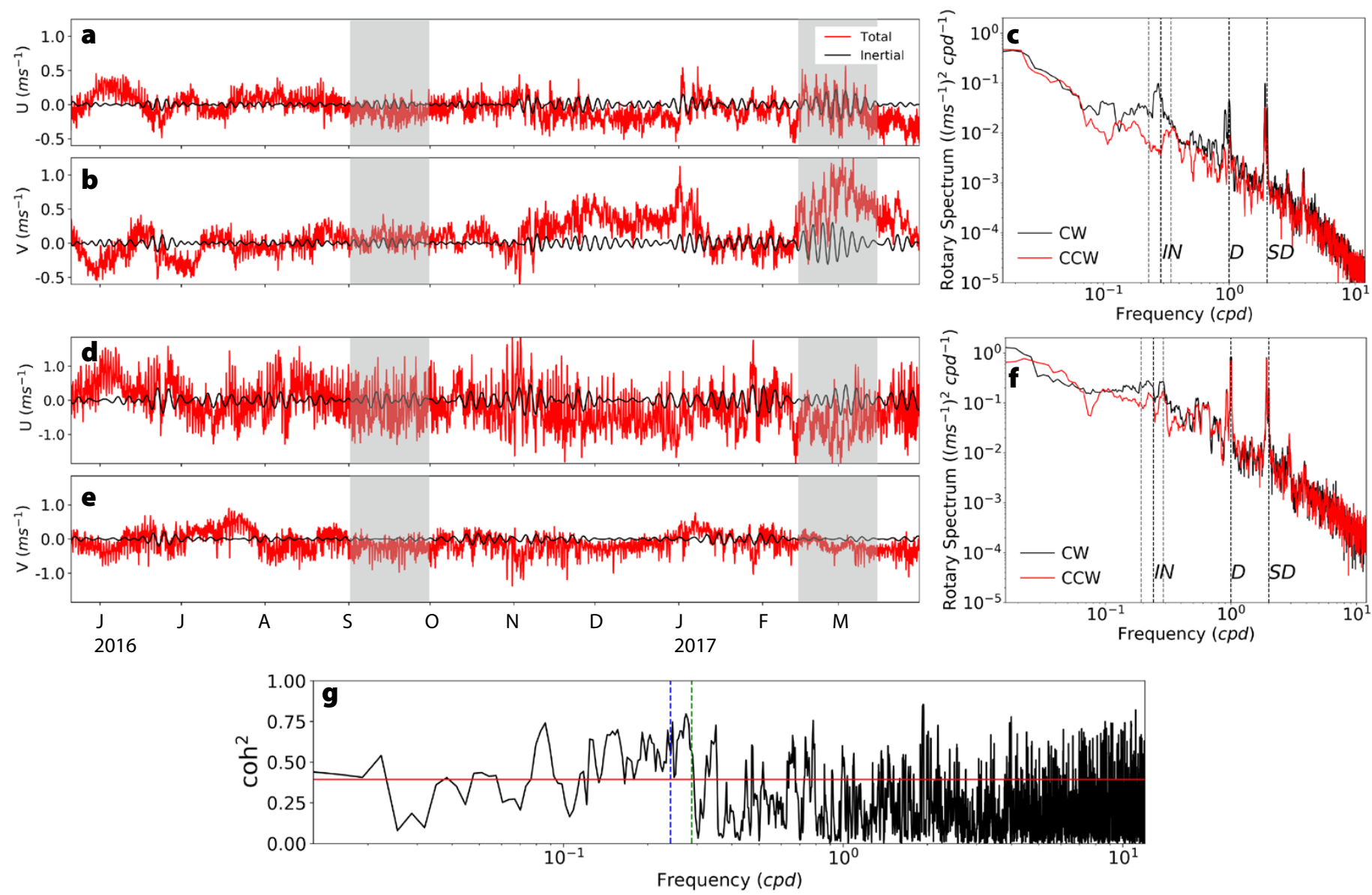

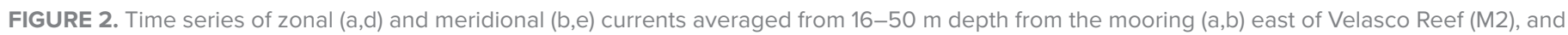

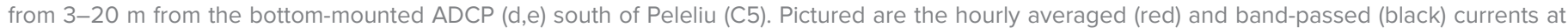

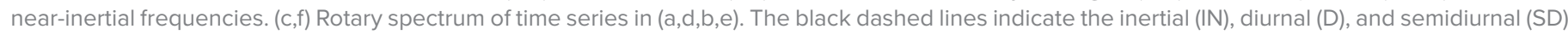

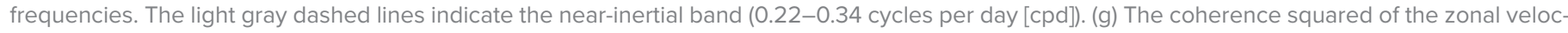

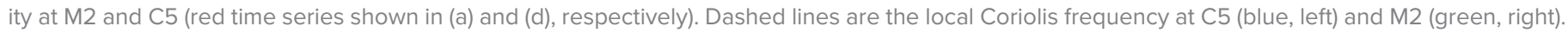
Red horizontal line is the $95 \%$ confidence limit. 
variance at $\mathrm{M} 2$ and $\mathrm{C} 5$, respectively. At the northern moorings, where measurements below $50 \mathrm{~m}$ depth were collected ( $\mathrm{M}$ and $\mathrm{F}$ ), near-inertial currents are at least twice as strong in the surface layer (typical speeds of $0.15 \mathrm{~m} \mathrm{~s}^{-1}$ ) compared to below $50 \mathrm{~m}$. The weaker near-inertial currents below the mixed layer exhibit upward phase propagation (not shown), consistent with downward energy propagation that contributes to the decay of surface near-inertial energy.

In the data for the 10-month study period, the subinertial flow is highly variable, dominated by large fluctuations in both meridional and zonal components at Velasco Reef (Figure 2a,b). The overall complexity of the flow field is reflected in the surface geostrophic currents from AVISO satellite data, which show westward-propagating eddies and meanders associated with the North Equatorial Countercurrent (NECC) encountering the island. Early in the deployment (May 28-June 23, July 3-August 12), two eddies sweep through the mooring array from the west, as described in detail by Andres et al. (2019, in this issue). In mid-September, AVISO velocities indicate a dominant westward flow encountering Palau (Figure 3a). The flow appears to bifurcate around the island,

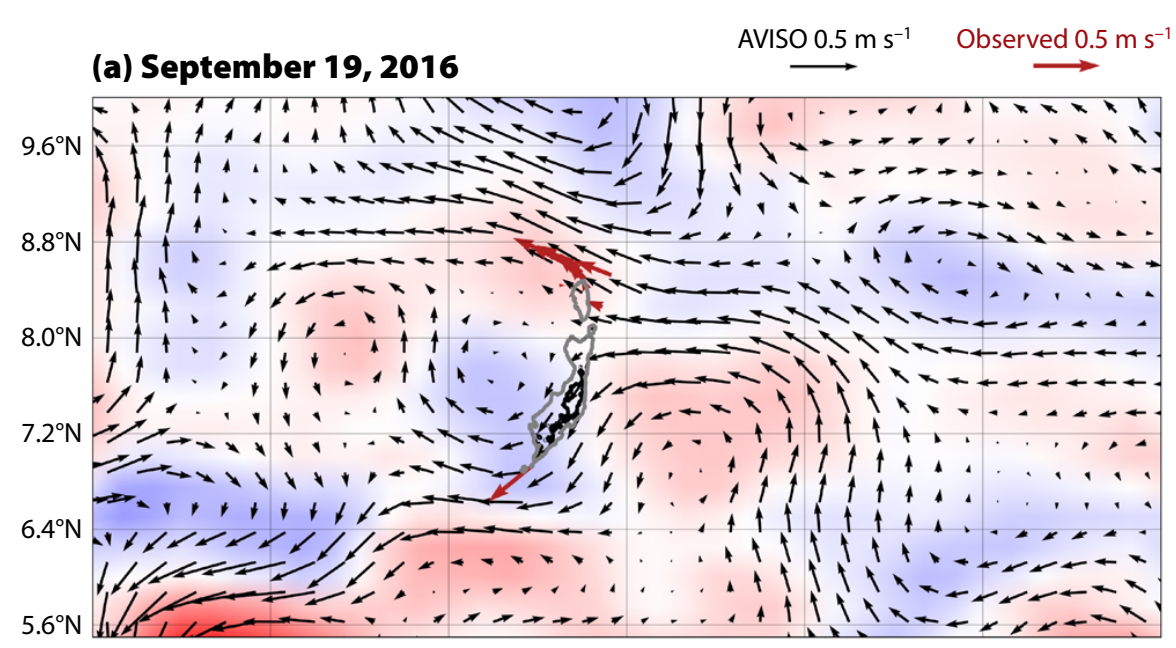

\section{(b) March 11, 2017}

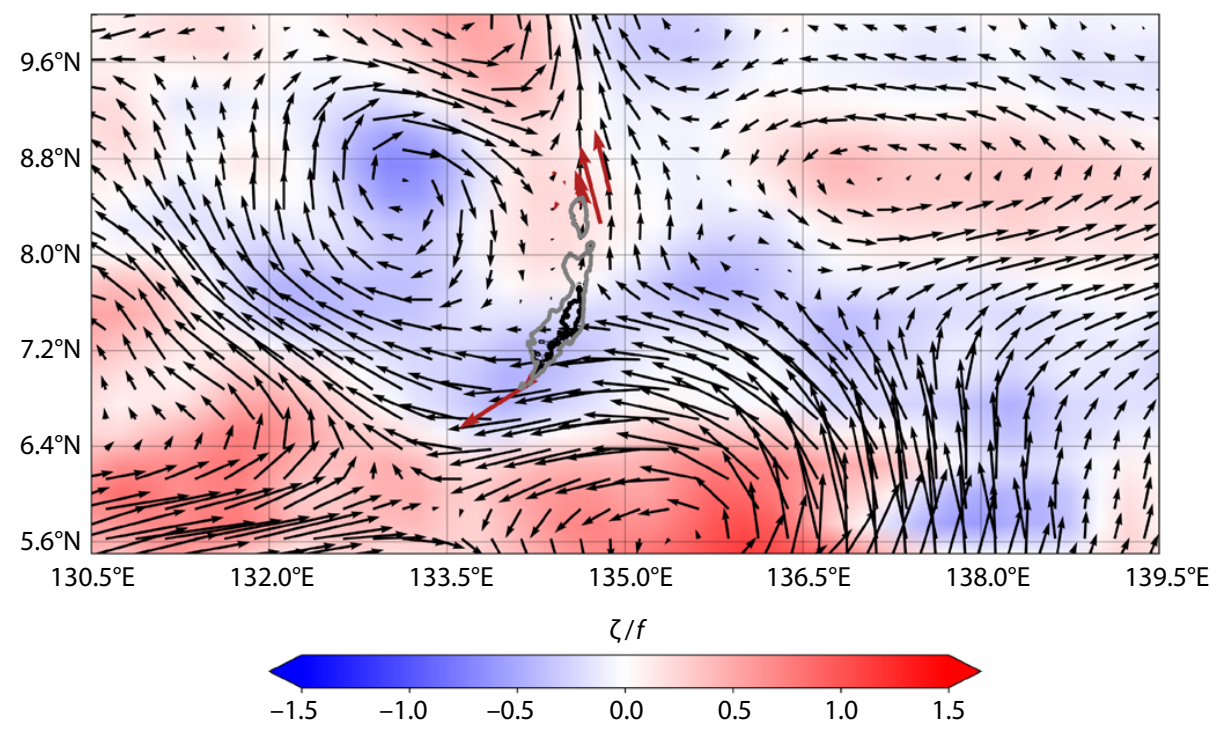

FIGURE 3. Relative vorticity normalized by the Coriolis frequency (f, color shading), computed using absolute surface geostrophic velocities from AVISO (black vectors). For comparison, dark red vectors indicate 10-day low-pass filtered surface currents from the FLEAT mooring array. Snapshots show periods when the geostrophic flow encountering Palau was (a) predominantly westward, consistent with North Equatorial Current flow, and (b) meandering, with a strong northward flow near Palau.

generating positive shear as it rounds the northern tip of Velasco Reef and negative shear as it rounds Peleliu. The northern positive shear is also reflected in the mooring array, indicating that the in situ observations might have captured the topographic blocking of the island and subsequent acceleration around the tips. From mid-February through mid-March, a highly energetic meander strikes the eastern side of Palau at a lower latitude than the September event. Despite their limitations in temporal and spatial resolution, the AVISO current estimates show northward flow along the northern extent of the island chain, in qualitative agreement with the in situ measurements (Figure 3b). Along the southern extent, AVISO seems to underestimate the southward deflection of the flow as it encounters the islands.

Observed near-inertial currents tend to be episodic, as depicted in bandpass filtered velocity time series over the nearinertial frequency band (Figure 2a,b,d,e). The most energetic event observed at M2 occurred from mid-February to mid-March during the large-scale flow meander depicted in Figure 3b. Nearinertial currents reached speeds of up to $0.30 \mathrm{~m} \mathrm{~s}^{-1}$ at M2 and $0.46 \mathrm{~m} \mathrm{~s}^{-1}$ at C5.

Near-inertial current fluctuations are significantly coherent between Velasco Reef and Peleliu, despite being separated by over $150 \mathrm{~km}$. The maximum coherence squared (0.80) between the zonal velocity at the M2 and C5 moorings occurs at 0.27 cycles per day (cpd), which is the mean of the local Coriolis frequencies at the northern (M2) and southern (C5) tips of Palau (Figure 2g). The squared coherence is not significant (0.37) for meridional components, presumably because the topography near Peleliu impedes the meridional component of the flow at C5 (Figure 2b,e). Interestingly, the rotary spectrum at mooring M2 (Figure 2c) exhibits a red shift (toward lower frequencies) of the peak frequency $(0.27 \mathrm{cpd})$ in the near-inertial band relative to the local Coriolis frequency $(0.29 \mathrm{cpd})$. The same shift was observed at all moorings 
deployed near Velasco Reef (not shown). Alternatively, at Peleliu (C5), there is a blue shift (toward higher frequencies) of the peak near-inertial frequency (0.29 cpd) relative to the local Coriolis frequency $(0.24 \mathrm{cpd})$. The local peak frequency in the near-inertial band appears to be set by the mean Coriolis frequency over the meridional length of the island rather than the local Coriolis frequency.

Surface layer near-inertial currents exhibit strong spatial variability around Palau, as depicted in standard deviation ellipses for near-inertial band flows (Figure 4). At moorings farthest from the coast at Velasco Reef (M1, F1, M2, and M5), the near-inertial ellipses are nearly circular and predominantly clockwise rotational, which is consistent with Northern Hemisphere, wind-generated NIOs. The near-inertial currents become more rectilinear approaching the coast, that is, the ratio of clockwise (CW) to counterclockwise (CCW) energy tends toward unity, and the ellipses are oriented in the alongshore direction (Figure 4). Along the east and west sides of Palau,

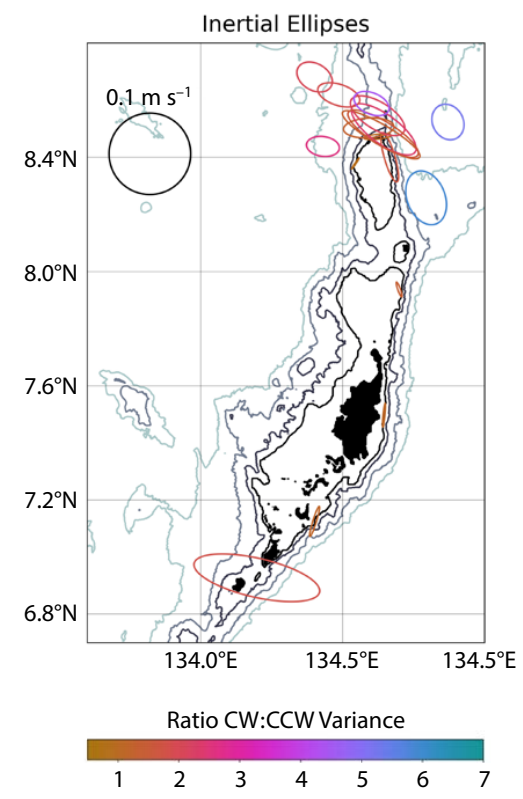

FIGURE 4. Inertial band (0.22-0.33 cpd) standard deviation ellipses are drawn at each mooring location. Each ellipse is colored by the ratio of clockwise to counterclockwise (CW:CCW) nearinertial variance. near-inertial currents are comparatively weak, most notably along the eastern side of Babeldaob (C1, C3, and C4) and the western side of Velasco Reef (B1). The diminished current amplitudes at these locations is consistent with previous studies of weakened near-inertial oscillations at continental coasts (Kundu et al., 1983; Tintoré et al., 1995). In contrast, the near-inertial currents observed near the northern tip of Velasco Reef and around the southern tip of Peleliu do not show signs of weakening. In fact, variance increases despite the close proximity of the currents to the island boundary, indicating flow acceleration.

To better understand the coherent relationship in the near-inertial band across the island, we calculated the empirical orthogonal functions (EOFs) of bandpassed near-inertial currents across the array. EOFs are a set of orthogonal basis functions that efficiently capture the dominant spatial and temporal variability of a data set (Thomson and Emery, 2014). Three sites (B3, B4, and M4) were not included in the EOF analysis due to

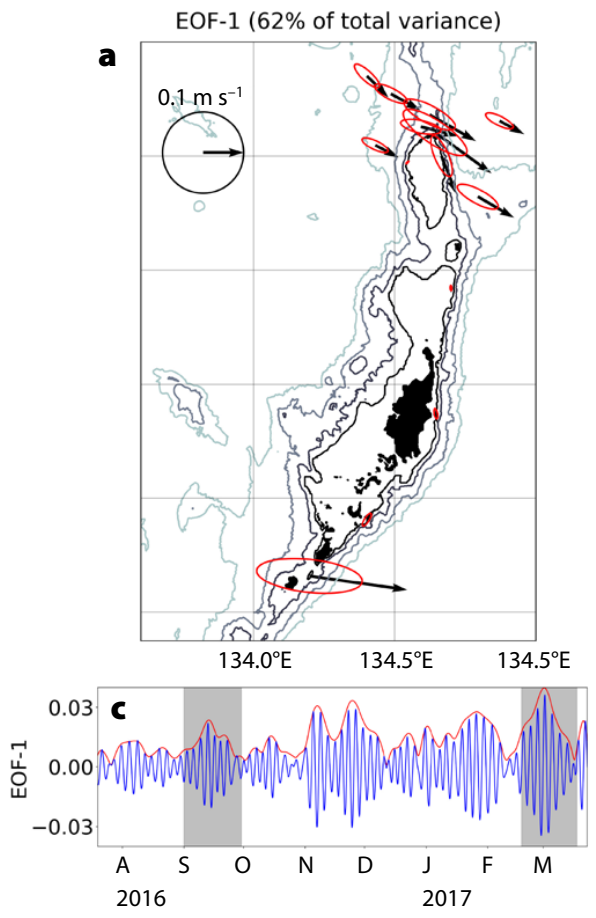

short record length (see Table 1), and one site (F4) was not included due to inconsistent surface layer sampling during the deployment. EOFs are calculated using current vector time series, which are de-meaned in time (see Kundu, 1976; Hardy and Walton, 1978; Kaihatu et al., 1998, for examples of EOFs of vector time series). An analysis of vector currents, as opposed to scalar components, is useful as the EOFs capture coherent rotary behavior, such as the tendency for CW rotating current vectors in time for NIOs. The first EOF accounts for $62 \%$ of the total near-inertial band variance (Figure 5a,c). The EOF-1 time series captures the episodic nature of the near-inertial currents (Figure $5 \mathrm{c}$ ). The complex demodulation amplitude of EOF-1 shows the most prominent event occurring between mid-February and mid-March, as previously discussed. The intermittent EOF-1 time series exhibits a dominant clockwise rotation. The standard deviation ellipses of the EOF-1 reconstructed velocities (Figure 5a) resemble the inertial ellipses in Figure 4, with enhanced energy around

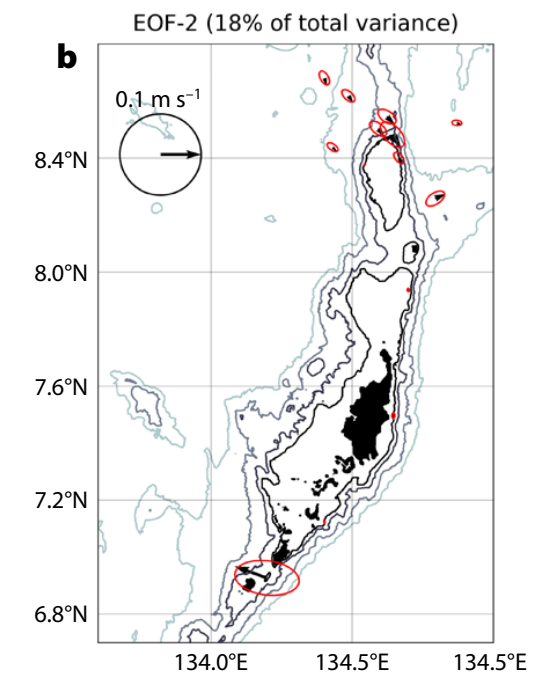

FIGURE 5. Standard deviation ellipses (in red) of the reconstructed velocities from (a) EOF-1, and (b) EOF-2. Black vectors are the reconstructed velocities on September 14, 2016, during peak nearinertial currents. The real component of the (c) EOF-1, and (d) EOF-2 time series (blue), and the complex demodulation of the complex time series (red). Gray boxes highlight time periods shown in Figure 6 of slab model comparisons to observations. 
the northern tip of Velasco Reef and the southern tip of Peleliu and weak energy along the eastern and western boundaries of the island. A snapshot of the EOF-1 reconstructed velocities (black vectors in Figure 5a) highlights the uniform direction of the currents at the northern and southern ends of the array. The covariability across the island chain implies that the near-inertial currents respond in unison to a high degree, which again points to wind stress as the primary generation mechanism. The second EOF accounts for $18 \%$ of the total near-inertial band variance (Figure 5b,d). Similar to EOF-1, the EOF-2 time series is clockwise rotational, but generates more circular ellipses than EOF-1. Reconstructing the velocities using only EOF-1 and EOF-2 results in circular standard deviation ellipses that are similar to the ellipses in Figure 4.

The EOF and coherence analyses suggest spatial uniformity in the near-inertial flow at both ends of Palau, which raises the question of whether wind forcing, with decorrelation scales larger than the island scale, can account for this motion. Using the slab model of Pollard and Millard (1970) and local wind forcing, we find the agreement between the model and the observations inconsistent. Because the inherent assumptions of the slab model are violated near a boundary, we highlight the comparison of the model with the observations furthest from topography (M5; Figure 6). At times, the slab model accurately reproduces the amplitude and phase of the observed near-inertial currents, for example, during the energetic event in September 2016 (Figure 6a). Qualitatively, there is strong agreement between the model and observed currents, which suggests that the nearinertial currents during this period were wind-generated. At other times the comparison is poor with notable phase disagreement, for example, during mid-February and mid-March (Figure 6b). The simplicity of the slab model (we made no attempt to optimize parameter choices) and the single island wind measurement used for forcing likely account for the limited skill; however, it is worth noting possible dynamics that

a

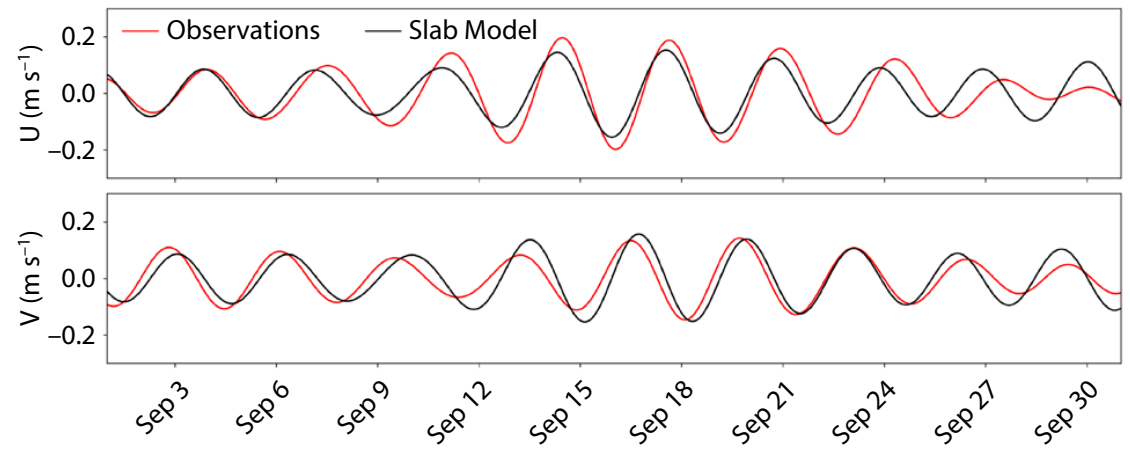

b
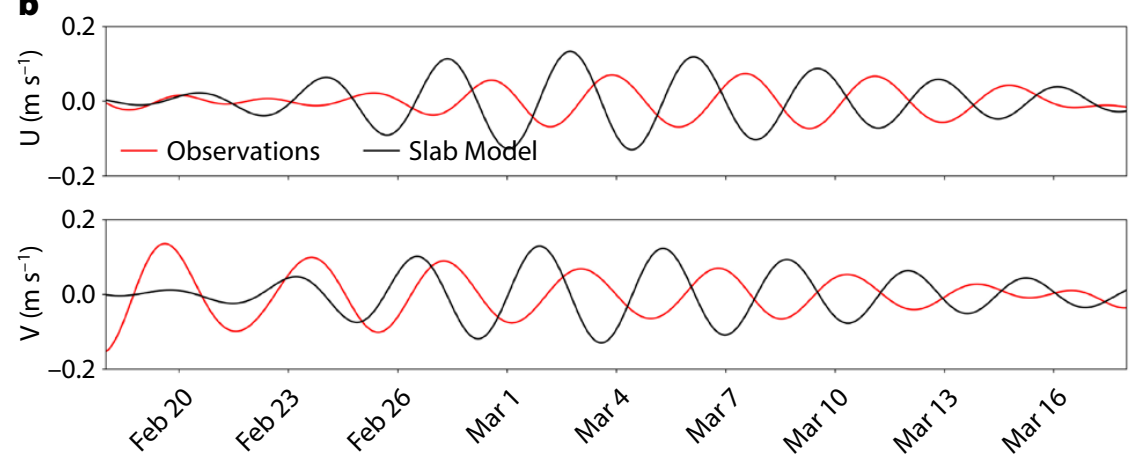

FIGURE 6. Near-inertial currents predicted by the slab model (black) and the observed nearinertial currents at M5 (red), located to the northeast of Velasco Reef from (a) September 1-30, 2016, and (b) February 18-March 18, 2017.

could contribute to poor model performance during the mid-February to midMarch event. Near-inertial oscillations can be modified by sheared subinertial currents (Weller, 1982; Kunze, 1985). During this period, geostrophic velocities, shown in Figure $3 b$, are highly laterally sheared across the mooring array. Moreover, the slab model performed well during the September event when the background shears were weak. We must also consider that mechanisms unrelated to winds, such as geostrophic adjustment, may have contributed to the observed NIOs. During the February-March event, an energetic subinertial flow occurs at Palau (Figure 3b). This encounter could cause instabilities in the low-frequency flow, resulting in the radiation of nearinertial internal waves and elevation of the near-inertial kinetic energy (Alford et al., 2013). In general, a generation mechanism linked to local flow adjustment would not account for the uniform EOF-1 spatial structure, as the subinertial currents are often different at the northern and southern ends of Palau (Schönau and Rudnick, 2015), reflected in the weak correlation of the 10-day lowpass zonal $\left(\mathrm{r}^{2}=0.26\right)$ and meridional $(\mathrm{r}=-0.23)$ velocities between Peleliu and Velasco Reef (M2). However, the ECMWF-predicted wind velocities are highly correlated at those two locations $\left(\mathrm{r}^{2}=0.84,0.78, \mathrm{u}, \mathrm{v}\right.$ component, respectively). We estimate the decorrelation length scale of the winds to be approximately $380 \mathrm{~km}$ during the deployment period, long enough to excite coherent NIOs across the entire island chain. This suggests that even though the simple slab model does not fully capture the variability of NIOs around Palau, there is strong evidence that they are primarily wind generated.

While the energetic subinertial flows around Palau are likely a complicating factor, the observations suggest that wind events occasionally excite NIOs that are coherent over the scale of the island chain. The NIOs are blocked by Palau's topography, creating areas of enhanced and diminished near-inertial current ampli- 
tudes. The notion that wind-driven NIOs on the island scale are governed by the island topography as a whole is consistent with the finding that the dominant frequency of oscillation in the near-inertial band is set by the mean Coriolis frequency over the island chain, and not by the local frequency.

\section{Vorticity Generation by}

\section{Near-Inertial Oscillations}

Recent studies at Velasco (MacKinnon et al., 2019; Zeiden et al., 2019) and Peleliu (Johnston et al., 2019, in this issue) suggest that swift currents at these sites generate wake eddies with strong local vorticity. To explore the extent to which NIOs contribute to island wakes, we use the surface-averaged currents from the mooring array deployed to the north of Velasco Reef (red circles in Figure 1) to compute the vertical component of vorticity (Figure 7a, moorings F2, F3, and F6). The principal axis of the observed velocity averaged over the three moorings (Figure 7a) is oriented with positive flow directed $67^{\circ}$ counterclockwise from true north, which generally matches the major axis of the standard deviation ellipses in Figure 4. Periods of sustained northwestward flow generate persistent positive vorticity, while periods of southeastward flow result in negative vorticity. The variance of the horizontal shear contributing to the vorticity is 2.5 times greater in $\partial v / \partial x$ compared to $\partial u / \partial y$. The direction of the principal axis and the strong shear contributed by $\partial v / \partial x$ suggest the importance of topographic blocking and a northward steering of the flow at the mooring array. Although the vorticity estimate likely reflects conditions outside the frictional boundary layer of the reef, the relationship between flow and vorticity is consistent with expected shear generated due to lateral friction as flow circumvents the island.

While the local currents and the vorticity estimate clearly covary (Figure 7a), the relationship is quantified further by calculating the cross spectrum between the two time series (Figure 7b). The low- frequency components of the time series are significantly coherent (Figure 7b) with minimal phase shift (Figure 7c), consistent with periods of sustained strong subinertial flows generating maximum vorticity. Interestingly, the near-inertial band appears to be highly coherent, reaching a maximum squared coherence of 0.96 at $0.27 \mathrm{cpd}$ (Figure 7b), with the vorticity lagging the currents by $31^{\circ}$. This coherence suggests that NIOs contribute to the production of vorticity near Velasco Reef. The red shift of the peak nearinertial frequency relative to the local Coriolis frequency is consistent with the shift observed in current spectra across the Velasco Reef array. The frequency of maximum coherence is again $0.27 \mathrm{cpd}$, which is approximately the mean of the local Coriolis frequencies at Velasco Reef (M2) and Peleliu (C5). The peak frequency suggests that the mechanism that excites near-inertial vorticity is not simply local to Velasco Reef, but rather has spatial scales on the order of the entire island chain.
A spectrogram of the vorticity displays the time variability of the energy content as a function of frequency (Figure 8a). The vorticity time series includes energetic super-inertial frequency variations, most notably in the near-inertial and tidal bands. The spectrogram indicates that vorticity in the near-inertial band can occur without a corresponding vorticity increase in the subinertial band, as exemplified by the September 2016 event. This lack of corresponding vorticity during the event enables near-inertial vorticity generation to be studied without subinertial vorticity complicating the results. In the case of the September 2016 event, the slab model shows that the near-inertial currents were wind generated, while the spectrogram reveals strong vorticity in the near-inertial band, but weak in the subinertial. Although open ocean wind-generated NIOs are considered irrotational, those oscillations may shear against topography, creating a near-inertial component to the island wake.

Integrating the spectrograms of vor-
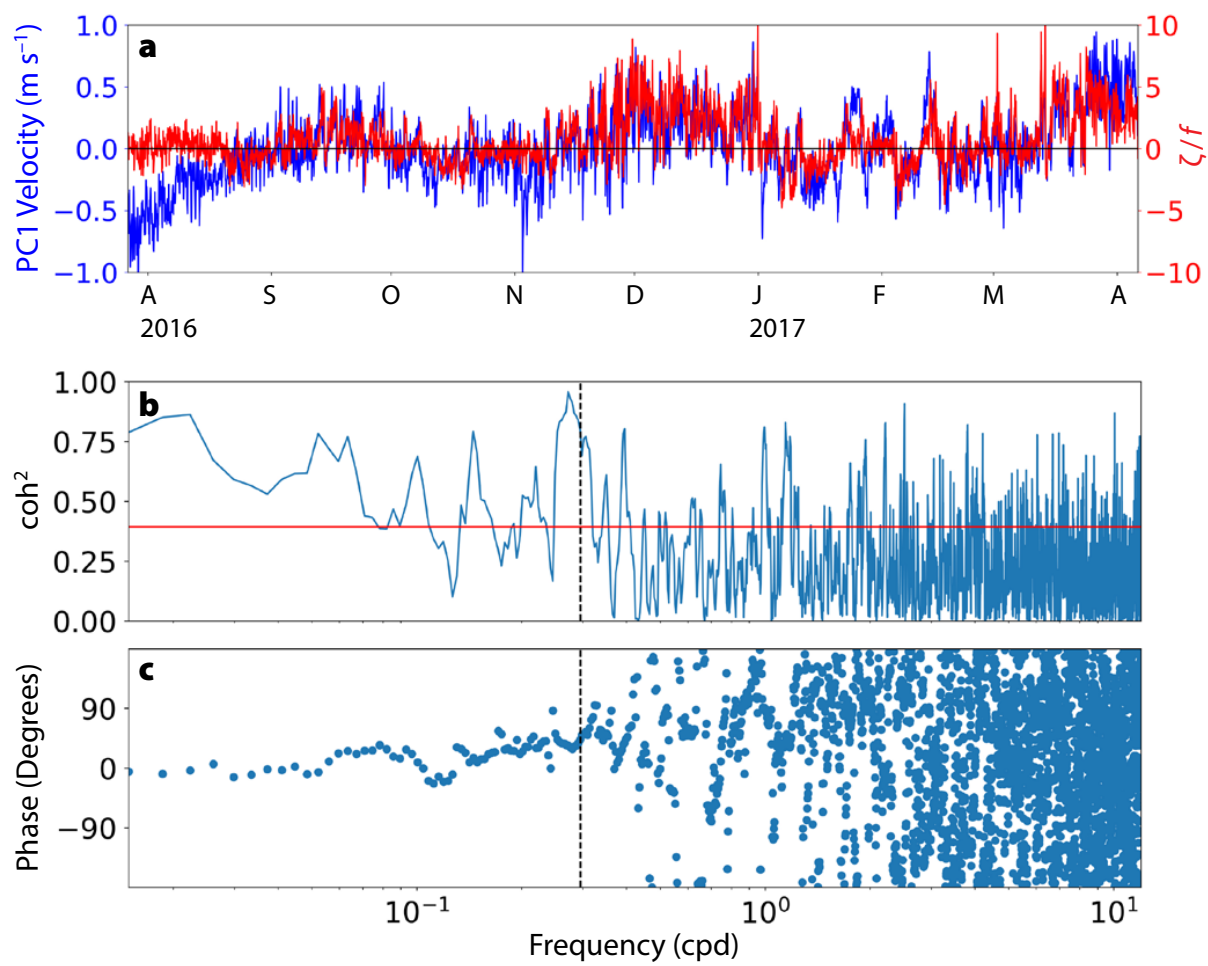

FIGURE 7. (a) The vertical component of vorticity estimated from depth-averaged surface currents $(16-50 \mathrm{~m})$ from the mooring array north of Velasco Reef, and normalized by $f$ (red) compared to the principal component of the mean currents averaged over the three moorings (F2, F3, and F6) used in the vorticity estimate (blue). The coherence (b) and phase difference (c) between the vorticity estimate and surface currents featured in panel (a). 
ticity and velocity (not shown) over the near-inertial band shows the episodic nature of the near-inertial variability in each time series (Figure 8b). During the September 2016 event, the running variance of near-inertial band vorticity and velocity appear related; however, the relationship is inconsistent throughout the record. The best correspondence occurs during July-December 2016 when subinertial currents are relatively weak. Beginning in January 2017, the correspondence breaks down when the subinertial current variability increases. The reasons for this shift and the relationship to subinertial currents are unclear.

\section{SUMMARY AND CONCLUSIONS}

One important motivation for this work is to understand island wakes, which contribute to the biological diversity around Palau by enhancing local mixing and transporting deep, nutrient-rich water to the surface. Here, we explore the role NIOs play in wake dynamics by characterizing their behavior near island topography and their contribution to vorticity generation.

Moored observations collected during the FLEAT experiment show that surface currents in the vicinity of Palau are energetic, complex, and broadband in frequency. The subinertial variability, also captured in AVISO geostrophic currents, features eddies and energetic meanders that lead to a highly variable flow in both amplitude and direction near Palau. Currents in the near-inertial band are energetic and episodic. The peak frequency of the near-inertial band is red shifted to the north of Palau and blue shifted to the south of Palau relative to the local Coriolis frequency, resulting in a peak frequency at both locations similar to the mean of the Coriolis frequency over the length of the island. In the far field, the near-inertial currents exhibit a dominant anticyclonic rotation, indicative of NIOs. Approaching topography, inertial currents become rectilinear and aligned with the island boundary. Coastal inhibition is observed at the west of Velasco Reef and to the east of Babeldaob, but the flow accelerates near the northern tip of Velasco Reef and the southern tip of Peleliu, resulting in enhanced amplitudes.

The vector EOF analysis shows that, to a high degree, the surface near-inertial currents rotate anticyclonically and in unison during energetic events. In particular, the enhanced flows at the northern tip of Velasco and the southern tip of Peleliu are related. This broad horizontal length scale is attributed to windgenerated NIOs. A slab model replicates observed currents sometimes, while at other times the relationship is poor, pre-
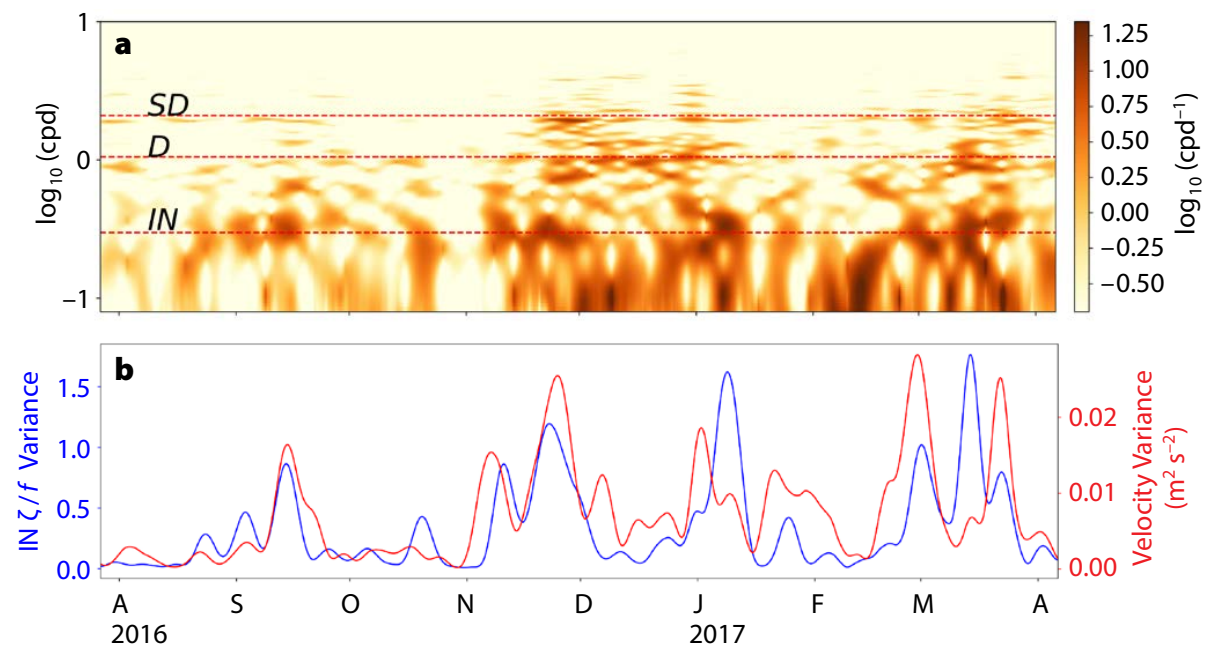

FIGURE 8. (a) Spectrogram of vorticity from the time series depicted in Figure 7a. The red dashed lines indicate semidiurnal (SD), diurnal (D), and inertial (IN) frequencies. (b) Time series of vorticity (blue) and velocity (red) variance from integrating spectrogram over the near-inertial frequency band.

sumably due to the single-point wind observations and the extreme simplicity of the model physics, missing, for example, the effects of the subinertial background velocity and the vorticity fields (Kunze, 1985; Elipot et al., 2010).

Vorticity calculated from moorings deployed near the northern tip of Velasco Reef exhibits episodes of elevated variance in the near-inertial band, indicating that NIOs contribute to vorticity generation when they shear against topography. MacKinnon et al. (2019) consider wake eddy generation in the presence of an oscillatory and a mean flow around the northern tip of Velasco Reef. While the oscillatory flow in that study was tidal, it seems likely that NIOs contribute to wake eddy formation at the northern and southern tips of Palau. In order to provide insight into how the phenomena discussed here contribute to local mixing and nutrient transport, additional field surveys and modeling studies are needed to estimate the properties of wake eddies at this timescale and to understand how open ocean NIOs meet boundary conditions imposed by islands. @

\section{REFERENCES}

Alford, M.H. 2001. Internal swell generation: The spatial distribution of energy flux from the wind to mixed layer near-inertial motions. Journal of Physical Oceanography 31(8):2,359-2,368, https://doi.org/10.1175/1520-0485(2001)031 $<2359$ :ISGTSD>2.0.CO;2.

Alford, M.H., and M.C. Gregg, 2001. Near-inertial mixing: Modulation of shear, strain and microstructure at low latitude. Journal of Geophysical Research 106(C8):16,947-16,968, https://doi.org/ 10.1029/2000JC000370.

Alford, M.H., A.Y. Shcherbina, and M.C. Gregg. 2013 Observations of near-inertial internal gravity waves radiating from a frontal jet. Journal of Physical Oceanography 43(6):1,225-1,239, https://doi.org/ 10.1175/JPO-D-12-0146.1.

Alford, M.H., J.A. MacKinnon, H.L. Simmons, and J.D. Nash. 2016. Near-inertial internal gravity waves in the ocean. Annual Review of Marine Science 8(1):95-123, https://doi.org/10.1146/ annurev-marine-010814-015746.

Andres, M., M. Siegelman, V. Hormann, R.C. Musgrave, S.T. Merrifield, D.L. Rudnick, M.A. Merrifield, M.H. Alford, G. Voet, H.W. Wijesekera, and others. 2019. Eddies, topography, and the abyssal flow by the Kyushu-Palau Ridge near Velasco Reef. Oceanography 32(4):46-55, https://doi.org/ 10.5670/oceanog.2019.410.

Colin, P.L. 2009. Marine Environments of Palau. Indo-Pacific Press, 416 pp.

Coutis, P.F., and J.H. Middleton. 1999. Flowtopography interaction in the vicinity of an isolated, deep ocean island. Deep Sea Research Part / 46(9):1,633-1,652, https://doi.org/10.1016/ S0967-0637(99)00007-2. 
D'Asaro, E.A. 1985. The energy flux from the wind to near-inertial motions in the surface mixed layer. Journal of Physical

Oceanography 15(8):1,043-1,059, https://doi.org/ 10.1175/1520-0485(1985)015<1043:TEFFTW> 2.0.CO;2.

D’Asaro, E.A., C.C. Eriksen, M.D. Levine, C.A. Paulson, P. Niiler, and P. Van Meurs. 1995. Upper-ocean inertial currents forced by a strong storm: Part I. Data and comparisons with linear theory. Journal of Physical Oceanography 25(11):2,909-2,936, https://doi.org/10.1175/1520-0485(1995)025<2909: UOICFB $>2.0 . \mathrm{CO} ; 2$

Dong, C., J.C. McWilliams, and A.F. Shchepetkin. 2007. Island wakes in deep water. Journal of Physical Oceanography 37(4):962-981, https://doi.org/10.1175/JPO3047.1.

Elipot, S., R. Lumpkin, and G. Prieto. 2010. Modification of inertial oscillations by the mesoscale eddy field. Journal of Geophysical Research 115(C9), https://doi.org/10.1029/ 2009JC005679.

Firing, E., R.-C. Lien, and P. Muller. 1997. Observations of strong inertial oscillations after the passage of tropical cyclone Ofa. Journal of Geophysical Research 102(C2):3,317-3,322, https://doi.org/ 10.1029/96JC03497.

Fontán, A., and B. Cornuelle. 2015. Anisotropic response of surface circulation to wind forcing, as inferred from high-frequency radar currents in the southeastern Bay of Biscay. Journal of Geophysical Research 120(4):2,945-2,957, https://doi.org/10.1002/2014JC010671.

Gove, J.M., M.A. McManus, A.B. Neuheimer J.J. Polovina, J.C. Drazen, C.R. Smith, M.A. Merrifield, A.M. Friedlander, J.S. Ehses, C.W. Young, and others. 2016. Near-island biological hotspots in barren ocean basins. Nature Communications 7:10581, https://doi.org/10.1038/ ncomms10581.

Hardy, D.M., and J.J. Walton. 1978. Principal components analysis of vector wind measurements. Journal of Applied Meteorology 17(8):1,153-1,162, https://doi.org/10.1175/1520-0450(1978)017<1153: PCAOVW>2.0.CO:2.

Heywood, K.J., E.D. Barton, and J.H. Simpson. 1990. The effects of flow disturbance by an oceanic island. Journal of Marine Research 48(1):55-73, https://doi.org/10.1357/002224090784984623.

Johnston, T.M.S., and D.L. Rudnick. 2009. Observations of the transition layer. Journa of Physical Oceanography 39(3):780-797, https://doi.org/10.1175/2008JP03824.1.

Johnston, T.M.S., D. Chaudhuri, M. Mathur, D. Sengupta, H.L. Simmons, A. Tandon, and R. Venkatesan. 2016. Decay mechanisms of near-inertial mixed layer oscillations in the Bay of Bengal. Oceanography 29(2):180-191, https://doi.org/10.5670/oceanog.2016.50.

Johnston, T.M.S., J.A. MacKinnon, P.L. Colin, P.J. Haley Jr., P.F.J. Lermusiaux, A.J. Lucas, M.A. Merrifield, S.T. Merrifield, C. Mirabito, J.D. Nash, and others. 2019. Energy and momentum lost to wake eddies and lee waves generated by the North Equatorial Current and tidal flows at Peleliu, Palau. Oceanography 32(4):110-125, https://doi.org/10.5670/oceanog.2019.417.

Kaihatu, J.M., R.A. Handler, G.O. Marmorino, and L.K. Shay. 1998. Empirical orthogonal function analysis of ocean surface currents using complex and real-vector methods. Journal of Atmospheric and Oceanic Technology 15(4):927-941, https://doi.org/10.1175/1520-0426(1998)015<0927: EOFAOO $>2.0 . C O ; 2$

Kundu, P.K. 1976. An analysis of inertial oscillations observed near Oregon coast. Journal of Physical Oceanography 6(6):879-893, https://doi.org/ 10.1175/1520-0485(1976)006<0879:AAOIOO> 2.0.CO;2.
Kundu, P.K., S.-Y. Chao, and J.P. McCreary. 1983. Transient coastal currents and inertio-gravity waves. Deep Sea Research Part A 30(10):1,059-1,082, https://doi.org/ 10.1016/0198-0149(83)90061-4.

Kunze, E. 1985. Near-inertial wave propagation in geostrophic shear. Journal of Physical Oceanography 15(5):544-565, https://doi.org/ 10.1175/1520-0485(1985)015<0544:NIWPIG> 2.0.CO;2

Large, W.G., and S. Pond. 1981. Open ocean momentum flux measurements in moderate to strong winds. Journal of Physical Oceanography 11(3):324-336, https://doi.org/ 10.1175/1520-0485(1981)011<0324:0OMFMI> 2.0.CO;2.

Longuet-Higgins, M.S. 1970. Steady currents induced by oscillations round islands. Journal of Fluid Mechanics 42(4):701-720, https://doi.org/10.1017/ S0022112070001568.

MacKinnon, J.A., M.H. Alford, G. Voet, K. Fitzmorris T.S. Johnston, M. Siegelman, S. Merrifield, and M. Merrifield. 2019. Eddy wake generation from broadband currents near Palau. Journal of Geophysical Research 124:4,891-4,903, https://doi.org/10.1029/2019JC014945.

Paduan, J.D., R.A. de Szoeke, and R.A. Weller. 1989. Inertial oscillations in the upper ocean during the mixed layer dynamics experiment (MILDEX). Journal of Geophysical Research 94(C4):4,835-4,842, https://doi.org/ 10.1029/JC094iC04p04835.

Pattiaratchi, C., A. James, and M. Collins. 1987. Island wakes and headland eddies: A comparison between remotely sensed data and laboratory experiments. Journal of Geophysical Research 92(C1):783-794, https://doi.org/10.1029/ JC092iC01p00783.

Pollard, R.T., and R. Millard. 1970. Comparison between observed and simulated wind-generated inertial oscillations. Deep Sea Research and Oceanographic Abstracts 17(4):813-821, https://doi.org/10.1016/0011-7471(70)90043-4.

Pollard, R.T. 1980. Properties of near-surface inertial oscillations. Journal of Physical Oceanography 10(3):385-398, https://doi.org/ 10.1175/1520-0485(1980)010<0385:PONSIO> 2.0.CO;2.

Price, J.F., T.B. Sanford, and G.Z. Forristall. 1994. Forced stage response to a moving hurricane. Journal of Physical Oceanography 24(2):233-260, https://doi.org/10.1175/1520-0485(1994)024<0233: FSRTAM $>2.0 . \mathrm{CO} ; 2$.

Schahinger, R.B. 1988. Near-inertial motion on the south Australian shelf. Journal of Physical Oceanography 18(3):492-504, https://doi.org/ 10.1175/1520-0485(1988)018<0492:NIMOTS> 2.0.CO;2.

Schönau, M.C., and D.L. Rudnick. 2015. Glider observations of the North Equatorial Current in the western tropical Pacific. Journal of Geophysical Research 120(5):3,586-3,605, https://doi.org/ 10.1002/2014JC010595.

Shay, L.K., and R.L. Elsberry. 1987. Near-inertial ocean current response to Hurricane Frederic. Journal of Physical Oceanography 17(8):1,249-1,269, https://doi.org/10.1175/1520-0485(1987)017<1249: NIOCRT>2.0.CO;2.

Shearman, R.K. 2005. Observations of nearinertial current variability on the New England shelf. Journal of Geophysical Research 110(C2), https://doi.org/10.1029/2004JC002341.

Simmons, H.L., and M.H. Alford. 2012. Simulating the long-range swell of internal waves generated by ocean storms. Oceanography 25(2):30-41, https://doi.org/10.5670/oceanog.2012.39.

Thomson, R.E., and W.J. Emery. 2014. Data Analysis Methods in Physical Oceanography, $3^{\text {rd }}$ ed., Elsevier, $728 \mathrm{pp}$

Tintoré, J., D.-P. Wang, E. Garćia, and A. Viúdez. 1995. Near-inertial motions in the coastal ocean. Journal of Marine Systems 6(4):301-312, https://doi.org/ 10.1016/0924-7963(94)00030-F.
Trujillo, A. 2018. Ocean Dynamics South Shore of O'ahu, Hawai'i: From Mean Circulation to NearInertial Waves and Submesoscale. Doctoral dissertation, University of Hawai'i.

Weller, R.A. 1982. The relation of near-inertial motions observed in the mixed layer during the JASIN (1978) experiment to the local wind stress and to the quasi-geostrophic flow field. Journal of Physical Oceanography 12(10):1,122-1,136, https://doi.org/10.1175/1520-0485(1982)012<1122: TRONIM>2.0.CO;2.

Wolanski, E., J. Imberger, and M. Heron. 1984. Island wakes in shallow coastal waters. Journa of Geophysical Research 89:10,553-10,569, https://doi.org/10.1029/JC089iC06p10553.

Zeiden, K.L., D.L. Rudnick, and J.A. MacKinnon. 2019. Glider observations of a mesoscale oceanic island wake. Journal of Physical Oceanography 49(9):2,217-2,235, https://doi.org/10.1175/JPO-D-18-0233.1.

\section{ACKNOWLEDGMENTS}

We want to express our deepest thanks to the many people who contributed to the success of the field experiment. Captain Murline, the crew of R/V Revelle, and the engineers from the Multiscale Ocean Dynamics group at Scripps Institution of Oceanography spared no effort in helping us complete our mooring deployments. Derek Young's creativity, versatility, and ingenuity were invaluable in overcoming a diverse range of issues that arose in conducting our fieldwork. Pat and Lori Colin at the Coral Reef Research Foundation provided crucial assistance during the FLEAT experiment. We also thank the Palau National Government for permission to carry out the research in Palau. Finally, we'd like to thank Bia Villas Bôas and Ruth Musgrave for many fruitful conversations. Our work was supported by Office of Naval Research grant numbers N00014-16-1 2671, N00014-15-1-2264, N00014-15-1-2592, N0001416-1-3070, and N00014-15-1-2304.

\section{AUTHORS}

Mika Siegelman (msiegelm@hawaii.edu) is a graduate student at the University of Hawai'i at Mānoa, Honolulu, HI, USA. Mark A. Merrifield is Professor, Scripps Institution of Oceanography, University of California San Diego, La Jolla, CA, USA. Eric Firing is Professor, University of Hawai'i at Mānoa, Honolulu, $\mathrm{HI}$, USA. Jennifer A. Mackinnon is Professor, Matthew H. Alford is Professor, and Gunnar Voet is Assistant Project Scientist, all at Scripps Institution of Oceanography, University of California San Diego, La Jolla, CA, USA. Hemantha W. Wijesekera is Oceanographer, Naval Research Laboratory, Stennis Space Center, MS, USA. Travis A. Schramek is an oceanographer, Kristin L. Zeiden is a graduate student, and Eric J. Terrill is Director, Coastal Observing Research and Development Center, all at Scripps Institution of Oceanography, University of California San Diego, La Jolla, CA, USA

\section{ARTICLE CITATION}

Siegelman, M., M.A. Merrifield, E. Firing,

J.A. MacKinnon, M.H. Alford, G. Voet, H.W. Wijesekera, T.A. Schramek, K.L. Zeiden, and E.J. Terrill. 2019 Observations of near-inertial surface currents at Palau. Oceanography 32(4):74-83, https://doi.org/ 10.5670/oceanog.2019.413.

\section{COPYRIGHT \& USAGE}

This is an open access article made available unde the terms of the Creative Commons Attribution 4.0 International License (https://creativecommons.org/ licenses/by/4.0/), which permits use, sharing, adaptation, distribution, and reproduction in any medium or format as long as users cite the materials appropriately, provide a link to the Creative Commons license, and indicate the changes that were made to the original content. 